\title{
Practicing Ecological Restoration: Climate Change in Context
}

G lobal climate change surely provides ecological restoration with major opportunities but also some large challenges. Scientific consensus on human-induced climate change has strengthened with every assessment issued by the United Nations Intergovernmental Panel on Climate Change, with the fourth assessment, released last year, stating, "warming of the climate system is unequivocal” (IPCC 2007).

Much has been said about how ecological restoration can help people mitigate, adapt to, and recover from negative impacts of climate change. The Society for Ecological Restoration International issued a position statement at its 2007 annual meeting in San Jose, California, stating that ecological restoration is a critical tool to address global climate change, enhancing the extent and functioning of carbon sinks as well as reducing greenhouse gas emissions. By restoring wetlands and other natural areas, ecological restoration can increase carbon sequestration and lower human vulnerability to flooding and extreme climatic events. Restored and resilient ecosystems can better provide a broad range of ecological services such as the production of clean water, ecological processes like pollination, the preservation of biodiversity, and potential future options, human inspiration, and cultural continuity (Daily 2000).

On the other hand, climate change also presents challenges to ecological restoration, especially in the loss of a historically defined, obtainable reference ecosystem as a restoration target. The concept of a near future irrevocably changed from the past opens up difficult questions about the role of history in establishing project objectives and in distinguishing ecological restoration from conservation. At worst, climate change might render the practice obsolete, or relegate it to being an expensive hobby.

Indeed, global climate change promises a whole new context for restoration: managing for the unexpected. Not only does the future hold increased potential for extreme weather events, but more critically it promises a high level of uncertainty about fundamental processes. The very basic patterns of seasonality and weather stability upon which ecological management has been based (annual rainfall and

Ecological Restoration Vol. 27, No. 3, 2009

ISSN 1522-4740 E-ISSN 1543-4079

( 2009 by the Board of Regents of the University of Wisconsin System. temperature norms) cannot be taken for granted. Climate change thus introduces a new level of uncertainty to both setting objectives for and managing restorations.

Climate change has the potential to provide tremendous impetus for restoration in terms of political will, funding, and direct participation (see the essay by David Havlick and Martin Doyle in this issue). At the same time that climate change is getting more scientific and public attention, however, ecological restoration may get less, if the value of restoration is not made clear.

This issue of Ecological Restoration contains a collection of Restoration Notes and full-length articles dedicated to the theme of climate change and ecological restoration. Peter Dunwiddie and his colleagues present models for landscape-level thinking about biodiversity conservation, restoration, and management that incorporate flexibility and redundancy in order to provide species and groups of species more options in the face of change. The authors describe the benefits and trade-offs of each of their models. Nat Seavy and his colleagues emphasize the importance of riparian restoration to prepare ecological systems for the threats posed by climate change and discuss some of the land use issues around rivers-patterns of ownership and watershed management policies - that will be critical in maintaining and expanding restoration of rivers in the future. James Barilla presents a reflective essay, based on his experience as a "voluntourist" in New Orleans, on the conundrums created by restoration of natural and human communities in the face of climate change. Colleagues from two sites in the Midwest, McHenry County Conservation District in Illinois and the University of Wisconsin-Madison Arboretum, share their thoughts on the "new nature" ushered in by climate change, how climate change might influence restoration goals based on historical conditions and such contemporary restoration and management issues as stormwater, extreme precipitation events, and changes in the effectiveness of restoration techniques.

Of course, many practitioners and land managers have been responding to the reality of climate change for some time. Articles in this issue reflect on how local climates have been changing and on the difficulty of identifying global climate as the driver of increases in mean temperatures, droughts, or flooding events. There can be many other possible culprits and confounding influences, 
such as urbanization, changes in land management, and legacy effects from a single historical event such as a fire, construction of a drainage canal, or disease outbreak.

Another theme that emerges from these articles and Restoration Notes is an expansion of the typical "objects of manipulation" (Harris et al. 2007). Authors frequently discuss not only biotic (nonhuman) and abiotic components critical for restoration projects, but also what might be called "contextual" components. Such contextual factors include distribution of property rights and public land as they might facilitate habitat connectivity, community stewardship and leadership for restoration management, the availability and expense of (often volunteer) labor to manage changing restoration technologies, and the possibilities for partnerships with a range of different groups in order to respond to unpredictable future change. From my reading of the pieces in this issue, along with articles published in other places, key contextual factors that restorationists are often addressing as they describe projects and management issues made more urgent by climate change fall into three broad categories: history, sources of stress, and relationships (the good, the bad, and the missing) of a restoration project.

Certainly history remains the paramount starting place for ecological restoration. Gathering data and overlaying spatial information about a physical landscape with human and nonhuman patterns of land use remains foundational for restoration efforts (Simpson 2009, Walker et al. 2002). A historical perspective provides information about previous associations between plants and animals, but also about previous land ownership and management and concomitant changes in the ecological landscape. It has been suggested that climate change means the end of history for ecological restoration, but the efforts reflected in this issue of Ecological Restoration suggest the opposite. In the context of uncertainty and change, history becomes more important than ever, because it provides a set of factors and events that can help project potential ecological trajectories (see Andy Clewell's piece in this issue). Climate change does suggest that we cast our chronological nets more widely - where in the past we may have limited our investigations to "presettlement conditions" in the 19th century, now we may have to make more efforts to explore evidence from much earlier time periods. No matter how unprecedented the particulars of our situation may be, catastrophic change of itself is not unique. Drawing on a wider pool of evidence may allow us to improve on models that are otherwise based on a rather narrow set of assumptions.

Sources of stress, and strategies for coping with stress, are other common elements in the discussion of ecological restoration and climate change. In their article in this issue, Peter Dunwiddie and his colleagues describe such coping strategies as creating redundancy and connectivity. Most managers of restoration projects can list a series of contemporary negative impacts deriving from human development including fragmentation, isolation, pollution, and stormwater runoff. All of these require that managers think through a number of strategies to respond to increasing vulnerability. For example, at the University of Wisconsin-Arboretum, increasing urbanization has placed limits on the number of days suitable for burning prairie. One tactic has been to increase the number of people trained to burn so that when a good burn day does arrive the required number of trained fire personnel are more likely to be on hand to make a burn happen.

Relationships between people, but also among people, plants, animals, and places influence restoration projects in a number of ways. Thinking broadly about relationships becomes an important part of developing strategies to respond to uncertainty or catastrophic events. For example, relationships exist not just between an endangered species and surrounding plants and animals, but also between that species and the legal system. Both kinds of relationships have profound influences on management; the presence of a recognized endangered species can mean government support for protecting and managing a habitat. Endangered species can also mean potentially negative relationships with nearby landowners, requiring particular responses like Safe Harbor Agreements, a point made by Seavy and his colleagues in their article in this issue. Some relationships are cultural: the Arboretum's Curtis Prairie, which was created in the 1930s and 1940s, enjoys a relatively well-established base of public awareness and tradition of institutional support from the University of Wisconsin. Relationships can also include partnerships with different groups to achieve common restoration goals, like those described by Laura Gephart of the Columbia River InterTribal Fish Commission in her Restoration Note.

Relationships can also be sources of conflict. For example, neighbors of a restored natural area may not appreciate what they see as a source of weeds or vermin if the restoration conflicts with established relationships and traditional uses of a place. Sometimes supporting relationships are not enough to guarantee recognition or protection, as John Kush documents in his Restoration Note in this issue on the demise of Alabama's Flomaton Natural Area.

Other critical relationships that restorationists consider are those that might be missing. Often there are missing relationships between such ecological elements as a plant and a pollinator, a channel and a floodplain, or a buried stream and the surrounding environment. But just as often, missing relationships are with people who, because of geographical proximity or historical relationships with a place, have the potential for strong and positive relationships to a restored area, but who may not be involved because of fewer resources or lack of experience. Seeking missing relationships requires the use of history but also a kind of proactive thinking and the development of a sense of appropriateness and ethics for valuing different restoration objectives. Although an undisputed historical target 
supposedly makes it easy to decide what "belongs" and what does not in a restoration, experience on the ground suggests that restoration projects require an appropriate deliberative process for including many voices, for considering and weighing interests, and understanding how those interests will influence restoration goals and management (Gobster and Hull 2000). Thus the process of restoration becomes as important as its target selection.

These kinds of discussions help anchor what can be an esoteric, wide-ranging conversation about the impacts of climate change. In response to the very general information we have about potential predicted regional temperature changes and increases in extreme climatic events, restoration managers are asking more specific questions about how the specific context of their project will influence resilience and vulnerability in times of change. Themes that emerge from these discussions include the importance of history, how to mitigate current sources of stress, and how to value and build positive relationships as part of a restoration process. Restoration provides people in many different places and positions with ways to engage in efforts to mitigate and adapt to climate change and to transform a frighteningly large, amorphous concept into a route toward concrete, positive environmental action.

On a final note, I would like to thank George Gann, outgoing chair of the Society for Ecological Restoration
International, for his informative and entertaining series of editorials in this journal over the past two years. I am also delighted to welcome Jim Harris, SERI's new chairperson. Please see his editorial in this issue.

Mrill Ingram

Editor

\section{References}

Daily, G.C. 2000. Management objectives for the protection of ecosystem services. Environmental Science \& Policy 3:333-339.

Gobster, P.H. and R.B. Hull. 2000. Restoring Nature: Perspectives from the Social Sciences and Humanities. Washington DC: Island Press.

Harris, J.A, R.J. Hobbs, E. Higgs and J. Aronson. 2006. Ecological restoration and global climate change. Restoration Ecology 14:170-176.

Intergovernmental Panel on Climate Change (IPCC). 2007. Climate change 2007: Synthesis report; Summary for policymakers. Valencia, Spain: IPCC. www.ipcc.ch/pdf/assessment-report/ ar4/syr/ar4_syr_spm.pdf

Simpson, T. 2009. A science of land individuals. Ecological Restoration 27:115-121.

Walker, B., S. Carpenter, J. Anderies, N. Abel, G. S. Cumming et al. 2002. Resilience management in social-ecological systems: A working hypothesis for a participatory approach. Conservation Ecology 6(1):14. www.consecol.org/vol6/iss1/art14/ 